\title{
An Order-Reduction Method of Interharmonic Analysis Model Based on the Principle of Interharmonic Interaction
}

\author{
Qingtian LUO, Qing ZHONG, Gang WANG, and Longjun WANG
}

\begin{abstract}
This paper presents a method on order-reduction of interharmonic analysis based on the principle of interharmonic interaction. First, we obtain the transformation between dynamic phasors in $d q$ coordinate and dynamic phasor sequence components (DPSCs). Then, a full-order interharmonic analysis model is developed taking the voltage and current double closed-loop controller into account via the transformation mentioned before. The principle of interharmonic interaction is studied based on the full-order DPSCs model. On the basis of the principle, the dominant frequencies for all kinds of variables are selected and a reduced-order interharmonic analysis model is derived. Finally, two examples are presented for illustration of the proposed method. It is shown that the reduced-order interharmonic analysis model based on the principle of interharmonic interaction keeps high accuracy with substantial computational savings.
\end{abstract}

Index Terms-Dynamic phasor sequence components (DPSCs), grid-connected PV system, interharmonic analysis, order-reduction, power quality, principle of interharmonic interaction.

\section{INTRODUCTION}

W ITH the increased use of power-electronic-based distributed generation (DG) systems, the presence of interharmonic components has introduced variations in waveform periodicity [1]-[4]. Interharmonic may cause problems such as harmonic amplification of resonant frequency, malfunction of protection, and excessive flicker of lamps [5]-[7]. Thus, the analysis of interharmonic plays a major role to understand power quality phenomena of DG systems and it is the premise to come up with mitigation schemes [8]-[10].

In the latest research, the interharmonic generated by gridconnected photovoltaic (PV) system has attracted widespread attention. Many attempts have been made to study the mechanism

Manuscript received June 10, 2021; revised July 28, 2021; accepted August 23, 2021. Date of publication September 30, 2021; date of current version September 24,2021 . This work was supported by the Natural Science Foundation of Guangdong Province, China under Grant 2021A1515012087. (Corresponding author: Qing Zhong.)

Q. Luo is with the South China University of Technology, Guangzhou, China and Guangdong Power Grid Corp Guangzhou Power Supply Bureau Co., Ltd., Guangzhou, China (e-mail: luoqingtian1996@qq.com).

Q. Zhong, G. Wang, and L. Wang are with the South China University of Technology, Guangzhou, China (e-mail: epqzhong@scut.edu.cn; wangg@scut.edu. cn; epwlj@scut.edu.cn).

Digital Object Identifier 10.24295/CPSSTPEA.2021.00019 and mitigation scheme of it [11]-[16]. The sources of interharmonic generated by grid-connected PV system can be separated into two types. One is the background interharmonic voltage which can be introduced by external interharmonic sources, such as voltage source inverter (VSI) fed drives and induction motors with oscillating mechanical loads. The other is the disturbance of reference dc voltage [17]-[18]. However, threephase grid-connected PV system has different interharmonic emission characteristics with single-phase ones. The interharmonic analysis model for three-phase grid-connected PV system can be divided into two types. One is the transfer function in frequency domain which can be used to assess the impact of the system parameters on interharmonic emission characteristics. The models in [19] only take $d$ coordinate into account so that the error will appear because of the coupling between $d q$ coordinates when there exists interharmonics in both coordinates. Besides, the method of transfer function is based on the small-signal model which may cause error when the disturbance is big enough [20]. The other is the method of dynamic harmonic domain (DHD) which is essentially the same as dynamic phasors (DPs) [21]-[25]. Modified dynamic harmonic domain (MDHD) is used to calculate the harmonics and interharmonics, which is a generalization of DHD by lowering the fundamental frequency [26]. However, small fundamental frequency will lead to high order when there exists interharmonics. To reduce the order of the equations in MDHD, flexible harmonic domain (FHD) is put forward by selecting dominant frequencies for each part or state variable of the system to reconstruct the Toeplitz matrix [27]. The corresponding method for transient state analysis is called flexible extended harmonic domain (FEHD) [28]. But, there is no knowledge about how to identify dominant frequencies in [27] and [28]. Both are used to establish interharmonic analysis model for PV system [29], [30]. While there is less illustration for the impact of the controller on the interharmonic emission in [30], maximum power point tracking (MPPT) control with proportional controller for boost and amplitude-phase control with proportional controller for inverter are taken into account in detail in [29]. Above all, recent literatures do not consider the effect of interharmonics on the controller. Because the cut-off frequency of sampling filter is much larger than the frequency of the interharmonics generated by grid-connected PV system, the interharmonic will be introduced into the controller. As a result, the controller will change the interharmonic emission 
characteristics of the grid-connected PV system. If the effect of interharmonics on the controller has to be considered in the interharmonic analysis, the order of the model will increase a lot, which will bring in the computational burden issues.

To reduce the order of the interharmonic analysis model, this paper proposed a method on order-reduction of interharmonic analysis model based on the principle of interharmonic interaction. In Section II, the transformations between DPs in $d q$ coordinate and dynamic phasor sequence components (DPSCs) are obtained by the $d q$ transformation matrix and the definition of DPs. Then, a full-order interharmonic analysis model of grid-connected PV system with double closed-loop controller is derived by selecting appropriate fundamental frequency. In Section III, the principle of interharmonic interaction is analyzed according to the full-order DPSCs model. Based on the principle of interharmonic interaction, a reduced-order interharmonic analysis model is derived by selecting the dominant frequencies for a variety of variables. In Section IV, simulation results are shown in order to validate the proposed method.

\section{Full-Order Interharmonic AnALysis Model}

\section{A. Transformation Between DPs in dq Coordinate and DPSCs}

Dynamic phasor (DP) is a frequency-selective averaging method based on the representation of a time-varying periodic signal $x(t)$ on the interval $[t-T, t]$ by the Fourier series

$$
x(t)=\sum_{k=-\infty}^{\infty} X_{k}(t) e^{j k \omega_{f} t},
$$

where $\omega_{f}=2 \pi f$ and the $X_{k}(t)$ are the complex Fourier coefficients. $f$ is the fundamental frequency of DPs model. These coefficients are functions of time and are given by

$$
X_{k}(t)=\frac{1}{T_{f}} \int_{t-T_{f}}^{t} x(\tau) e^{-j k \omega_{f} \tau} \mathrm{d} \tau,
$$

where $T_{f}=2 \pi / \omega_{f}$ and the $k$ th coefficient of the Fourier series is also referred to as the $k$ th DP. DPs have two key properties of derivative and convolution [23]. The definition given in (1) and (2) can be applied to poly-phase systems. For threephase cases, the DPs can be transformed into the DPSCs by symmetrical transformation as shown by

$$
\left[\begin{array}{l}
\left\langle X_{a(1)}\right\rangle_{k} \\
\left\langle X_{a(2)}\right\rangle_{k} \\
\left\langle X_{a(0)}\right\rangle_{k}
\end{array}\right]=\boldsymbol{T}\left[\begin{array}{l}
\left\langle X_{a}\right\rangle_{k} \\
\left\langle X_{b}\right\rangle_{k} \\
\left\langle X_{c}\right\rangle_{k}
\end{array}\right],
$$

where

$$
\boldsymbol{T}=\frac{1}{3}\left[\begin{array}{ccc}
1 & a & a^{2} \\
1 & a^{2} & a \\
1 & 1 & 1
\end{array}\right]
$$

in which $a=e^{j 120^{\circ}} .\left\langle X_{a}>_{k},\left\langle X_{b}\right\rangle_{k},\left\langle X_{c}>_{k}\right.\right.$ are the $k$ th DPs of $x(t)$ in phase $a, b$, and $c .\left\langle X_{a(1)}\right\rangle_{k},\left\langle X_{a(2)}\right\rangle_{k},\left\langle X_{a(0)}\right\rangle_{k}$ are the positive, negative, and zero sequence components of $k$ th DPs [25]. It should be noted that the coefficient of symmetrical transformation matrix in [24] is different from the one in [25]. According to the definition given in (3), two helpful properties are obtained. The derivatives of DPSCs are shown by (5).

$$
\frac{\mathrm{d}}{\mathrm{d} t}\left[\begin{array}{c}
\left\langle X_{a(1)}\right\rangle_{k} \\
\left\langle X_{a(2)}\right\rangle_{k} \\
\left\langle X_{a(0)}\right\rangle_{k}
\end{array}\right]=\boldsymbol{T}\left[\begin{array}{c}
\left\langle\frac{\mathrm{d} X_{a}}{\mathrm{~d} t}\right\rangle_{k} \\
\left\langle\frac{\mathrm{d} X_{b}}{\mathrm{~d} t}\right\rangle_{k} \\
\left\langle\frac{\mathrm{d} X_{c}}{\mathrm{~d} t}\right\rangle_{k}
\end{array}\right]-j k \omega_{f}\left[\begin{array}{l}
\left\langle X_{a(1)}\right\rangle_{k} \\
\left\langle X_{a(2)}\right\rangle_{k} \\
\left\langle X_{a(0)}\right\rangle_{k}
\end{array}\right]
$$

The conjugates of DPSCs are shown by

$$
\left[\begin{array}{l}
\left\langle X_{a(1)}\right\rangle_{-k} \\
\left\langle X_{a(2)}\right\rangle_{-k} \\
\left\langle X_{a(0)}\right\rangle_{-k}
\end{array}\right]=\left[\begin{array}{c}
\left\langle X_{a(2)}\right\rangle_{k}^{*} \\
\left\langle X_{a(1)}\right\rangle_{k}^{*} \\
\left\langle X_{a(0)}\right\rangle_{k}^{*}
\end{array}\right]
$$

where $\langle\cdot\rangle_{k}^{*}$ is the conjugate of $\langle\cdot\rangle_{k}$.

If we want to develop a DPSCs model for grid-connected PV system, we need to find out the transformation between DPs in $d q$ coordinate and DPSCs because the controller operates in $d q$ coordinate. The $d q$ transformation matrix in time domain (TD) is given by

$\left[\begin{array}{l}x_{d} \\ x_{q} \\ x_{0}\end{array}\right]=\frac{2}{3}\left[\begin{array}{ccc}\cos \alpha & \cos \left(\alpha-\frac{2}{3} \pi\right) & \cos \left(\alpha-\frac{4}{3} \pi\right) \\ -\sin \alpha & -\sin \left(\alpha-\frac{2}{3} \pi\right) & -\sin \left(\alpha-\frac{4}{3} \pi\right) \\ \frac{1}{2} & \frac{1}{2} & \frac{1}{2}\end{array}\right]\left[\begin{array}{l}x_{a} \\ x_{b} \\ x_{c}\end{array}\right]$,

where $\alpha=\omega_{\mathrm{s}} t . \omega_{\mathrm{s}}$ is the angular frequency of the system fundamental frequency. $x_{a}, x_{b}$, and $x_{c}$ are the variables in $a b c$ coordinate in TD. $x_{d}, x_{q}$, and $x_{0}$ are the variables in $d q$ coordinate in TD.

On the basis of the definition of DPs as given by (2), we got the $k$ th DPs of $x_{d}$ readily by substitute the cosine item in (7) with exponential function according to the Euler's formula as shown by

$$
\left\langle X_{d}\right\rangle_{k}=\left\langle X_{a(2)}\right\rangle_{k-l}+\left\langle X_{a(1)}\right\rangle_{k+l}
$$

where $l$ is the ratio of $\omega_{\mathrm{s}}$ to $\omega_{f}$.

Similarly, we got the $k$ th DPs of $x_{q}$ and $x_{0}$ as shown by (9) and (10).

$$
\begin{gathered}
\left\langle X_{q}\right\rangle_{k}=j\left\langle X_{a(2)}\right\rangle_{k-l}-j\left\langle X_{a(1)}\right\rangle_{k+l} \\
\left\langle X_{0}\right\rangle_{k}=\frac{1}{3}\left(\left\langle X_{a}\right\rangle_{k}+\left\langle X_{b}\right\rangle_{k}+\left\langle X_{c}\right\rangle_{k}\right)
\end{gathered}
$$




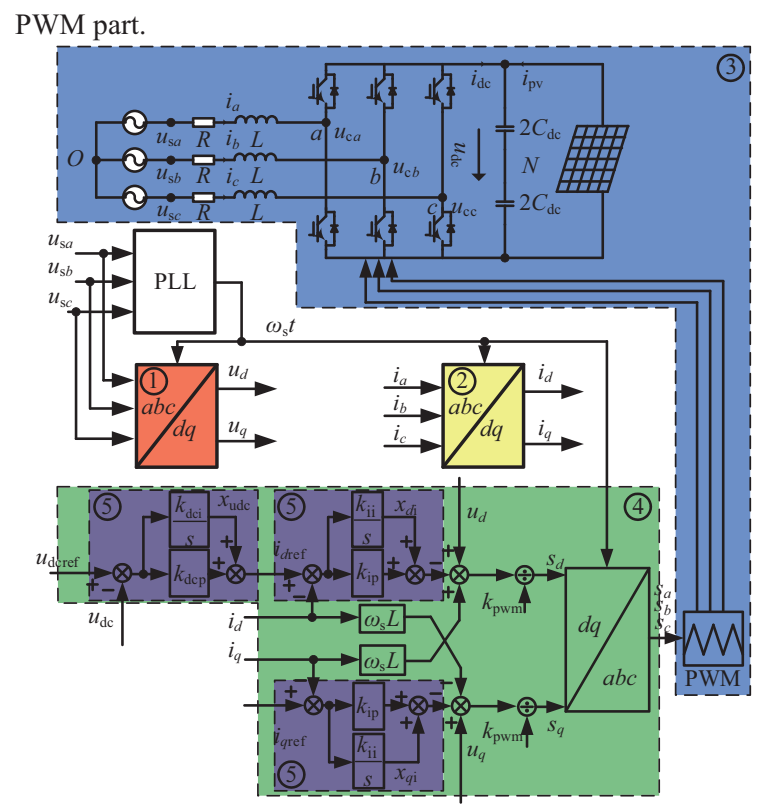

Fig. 1. Block diagram of a three-phase grid-connected PV system.

There is no component in zero-coordinate because of the three-wire application of three-phase grid-connected PV system. Therefore, the transformation from DPSCs to DPs in $d q$ coordinate are shown in (8) and (9).

In the same way, it is easy to get the transformation from DPs in $d q$ coordinate to DPSCs as shown in (11) and (12).

$$
\begin{aligned}
& \left\langle X_{a(1)}\right\rangle_{k}=\frac{1}{2}\left(\left\langle X_{d}\right\rangle_{k-l}+j\left\langle X_{q}\right\rangle_{k-l}\right) \\
& \left\langle X_{a(2)}\right\rangle_{k}=\frac{1}{2}\left(\left\langle X_{d}\right\rangle_{k+l}-j\left\langle X_{q}\right\rangle_{k+l}\right)
\end{aligned}
$$

\section{B. DPSCs Model}

The block diagram of a three-phase grid-connected PV system is shown in Fig. 1. The primary circuit as shown in Fig. 1 is considered, where an $L$-filter $L$ with a resistor $R$ is connected to the ac side. The dc-link capacitor $C_{\mathrm{dc}}$ is connected to the dcside. $u_{\mathrm{s} a}, u_{\mathrm{s} b}$, and $u_{\mathrm{sc}}$ are the source voltages. $i_{a}, i_{b}$, and $i_{c}$ are the inverter-side currents. $u_{\mathrm{c} a}, u_{\mathrm{c} b}$, and $u_{\mathrm{c} c}$ are the inverter-side voltages. $u_{\mathrm{dc}}$ is the dc voltage of the inverter. $i_{\mathrm{dc}}$ is the output current of the inverter on the dc side and $i_{\mathrm{pv}}$ is the dc current of PV. $s_{a}, s_{b}$, and $s_{c}$ are the phase switching functions representing the switching state of the power electronic devices. When the switch of the upper/lower arm is conducted, $s_{j}(j=a, b, c)$ is equal to $1 /-1$.

The controller is shown in Fig. 1. $u_{d q}, i_{d q}, i_{d q \text { ref }}$, and $s_{d q}$ are the source voltages, inverter-side currents, reference currents, and modulation waves in $d q$ coordinate. $u_{\text {dcref }}$ is the reference dc voltage. $x_{\text {udc }}, x_{d 1}$, and $x_{q \mathrm{i}}$ are the integral output of dc-voltage loop, $d$-current loop, and $q$-current loop. $k_{\mathrm{dcp}}, k_{\mathrm{dci}}, k_{\mathrm{ip}}$, and $k_{\mathrm{ii}}$ are the parameters of the PI-based controller. $k_{\mathrm{pwm}}$ is the gain of PWM part.

The DPSCs model of primary circuit whose derivation is illustrated in detail in [25] are shown by

$$
\begin{aligned}
& \frac{\mathrm{d}\left\langle I_{a(1)}\right\rangle_{k}}{\mathrm{~d} t}=-\frac{1}{2 L} \sum_{i}\left\langle S_{a(1)}\right\rangle_{k-i}\left\langle U_{\mathrm{dc}}\right\rangle_{i}- \\
& \left(\frac{R}{L}+j k \omega_{f}\right)\left\langle I_{a(1)}\right\rangle_{k}+\frac{\left\langle U_{s a(1)}\right\rangle_{k}}{L} \\
& \frac{\mathrm{d}\left\langle I_{a(2)}\right\rangle_{k}}{\mathrm{~d} t}=-\frac{1}{2 L} \sum_{i}\left\langle S_{a(2)}\right\rangle_{k-i}\left\langle U_{\mathrm{dc}}\right\rangle_{i}- \\
& \left(\frac{R}{L}+j k \omega_{f}\right)\left\langle I_{a(2)}\right\rangle_{k}+\frac{\left\langle U_{s a(2)}\right\rangle_{k}}{L} \\
& \frac{\mathrm{d}\left\langle U_{\mathrm{dc}}\right\rangle_{k}}{\mathrm{~d} t}=\frac{3}{2 C_{\mathrm{dc}}}\left(\sum_{i}\left\langle S_{a(1)}\right\rangle_{k-i}\left\langle I_{a(2)}\right\rangle_{i}+\right. \\
& \left.\sum_{i}\left\langle S_{a(2)}\right\rangle_{k-i}\left\langle I_{a(1)}\right\rangle_{i}\right)-j k \omega_{f}\left\langle U_{\mathrm{dc}}\right\rangle_{k}+\frac{\left\langle I_{\mathrm{pv}}\right\rangle_{k}}{C_{\mathrm{dc}}}(15)
\end{aligned}
$$

where $\left\langle U_{\mathrm{s} a(1)}\right\rangle_{k},\left\langle I_{a(1)}\right\rangle_{k}$, and $\left\langle S_{a(1)}\right\rangle_{k}$ are the $k$ th positive DPSCs of source voltage, inverter-side current, and modulation wave. $\left\langle U_{\mathrm{sa}(2)}\right\rangle_{k},\left\langle I_{a(2)}\right\rangle_{k}$, and $\left\langle S_{a(2)}\right\rangle_{k}$ are the $k$ th negative DPSCs of source voltage, inverter-side current, and modulation wave. $\left\langle U_{\mathrm{dc}}\right\rangle_{k}$ and $\left\langle I_{\mathrm{pv}}\right\rangle_{k}$ are the $k$ th DPs of dc voltage and dc current of PV. If the DPSCs model is applied to interharmonic analysis, we need to find out the appropriate fundamental frequency $(f)$ of DPSCs model which satisfy

$$
\left(\frac{f_{\mathrm{ac}, j}}{f} \in \mathbf{N}\right) \cap\left(\frac{f_{\mathrm{dc}, j}}{f} \in \mathbf{N}\right),
$$

where $f_{\mathrm{ac}, j}(j=1,2, \ldots)$ are the frequencies of ac disturbances and $f_{\mathrm{dc}, j}(j=1,2, \ldots)$ are the frequencies of dc disturbances.

The state equations and output equations of current controller can be represented according to Fig. 1 as (17)-(21).

$$
\begin{gathered}
\frac{\mathrm{d} x_{\mathrm{udc}}}{\mathrm{d} t}=u_{\mathrm{dcref}}-u_{\mathrm{dc}} \\
\frac{\mathrm{d} x_{d \mathrm{i}}}{\mathrm{d} t}=k_{\mathrm{dcp}}\left(u_{\mathrm{dcref}}-u_{\mathrm{dc}}\right)+k_{\mathrm{dci}} x_{\mathrm{udc}}-i_{d} \\
\frac{\mathrm{d} x_{q \mathrm{i}}}{\mathrm{d} t}=i_{q \mathrm{ref}}-i_{q} \\
s_{d}=\left\{-k_{\mathrm{ip}}\left[k_{\mathrm{dcp}}\left(u_{\mathrm{dcref}}-u_{\mathrm{dc}}\right)+k_{\mathrm{dci}} x_{\mathrm{udc}}-i_{d}\right]-\right. \\
\left.k_{\mathrm{ii}} x_{d \mathrm{i}}+\omega_{\mathrm{s}} L i_{q}+u_{d}\right\} / k_{\mathrm{pwm}} \\
s_{q}=\left[-k_{\mathrm{ip}}\left(i_{q \mathrm{ref}}-i_{q}\right)-k_{\mathrm{ii}} x_{q \mathrm{i}}-\omega_{\mathrm{s}} L i_{d}+u_{q}\right] / k_{\mathrm{pwm}}
\end{gathered}
$$

We can transform (17)-(21) into DPs model (Please refer to the Appendix for detail.) On the basis of Section II, the state equations and output equations of current controller in the form of DPSCs can be represented as

$$
\frac{\mathrm{d}\left\langle X_{\text {udc }}\right\rangle_{k}}{\mathrm{~d} t}=\left\langle U_{\text {dcref }}\right\rangle_{k}-\left\langle U_{\mathrm{dc}}\right\rangle_{k}-j k \omega_{f}\left\langle X_{\text {udc }}\right\rangle_{k}
$$




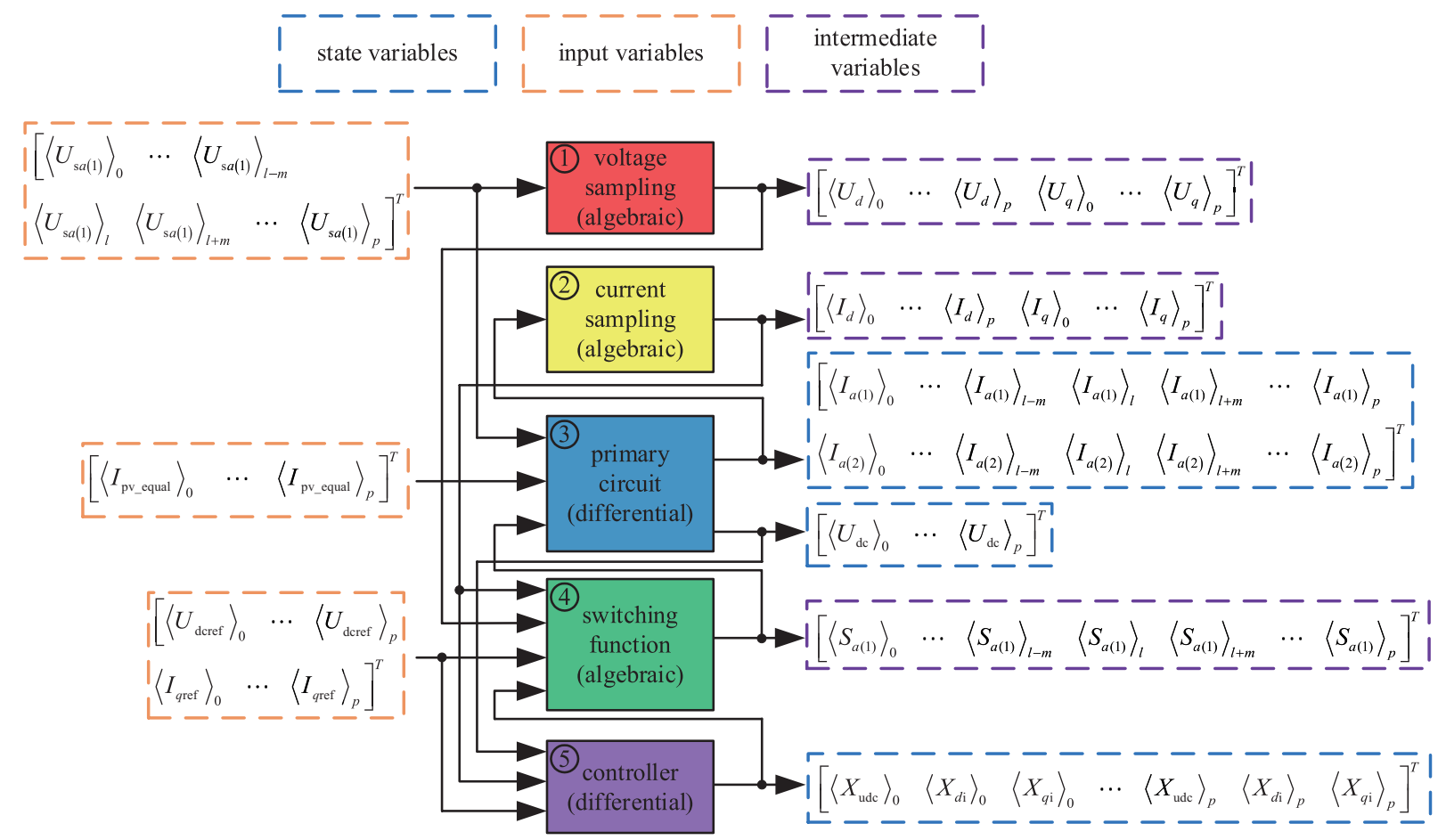

Fig. 2. Schematic diagram of the full-order interharmonic analysis model for grid-connected PV system.

$$
\begin{aligned}
& \frac{\mathrm{d}\left\langle X_{d \mathrm{i}}\right\rangle_{k}}{\mathrm{~d} t}= k_{\mathrm{dcp}}\left(\left\langle U_{\mathrm{dcref}}\right\rangle_{k}-\left\langle U_{\mathrm{dc}}\right\rangle_{k}\right)+k_{\mathrm{dci}}\left\langle X_{\mathrm{udc}}\right\rangle_{k}- \\
&\left(\left\langle I_{a(2)}\right\rangle_{k-l}+\left\langle I_{a(1)}\right\rangle_{k+l}\right)-j k \omega_{f}\left\langle X_{d \mathrm{i}}\right\rangle_{k} \\
& \frac{\mathrm{d}\left\langle X_{q \mathrm{i}}\right\rangle_{k}}{\mathrm{~d} t}=\left\langle I_{q \mathrm{ref}}\right\rangle_{k}-j\left(\left\langle I_{a(2)}\right\rangle_{k-l}-\left\langle I_{a(1)}\right\rangle_{k+l}\right)-j k \omega_{f}\left\langle X_{q \mathrm{i}}\right\rangle_{k} \\
&\left\langle S_{a(1)}\right\rangle_{k}= {\left[-k_{\mathrm{ip}} k_{\mathrm{dcp}}\left(\left\langle U_{\mathrm{dcref}}\right\rangle_{k-l}-\left\langle U_{\mathrm{dc}}\right\rangle_{k-l}\right)-\right.} \\
& k_{\mathrm{ip}} k_{\mathrm{dci}}\left\langle X_{\mathrm{udc}}\right\rangle_{k-l}+2\left(k_{\mathrm{ip}}-j \omega_{\mathrm{s}} L\right)\left\langle I_{a(1)}\right\rangle_{k}- \\
& k_{\mathrm{ii}}\left\langle X_{d \mathrm{i}}\right\rangle_{k-l}+2\left\langle U_{\mathrm{sa}(1)}\right\rangle_{k}-j k_{\mathrm{ip}}\left\langle I_{q \mathrm{ref}}\right\rangle_{k-l}- \\
&\left.j k_{\mathrm{ii}}\left\langle X_{q \mathrm{i}}\right\rangle_{k-l}\right] / 2 k_{\mathrm{pwm}} \\
&= {\left[-k_{\mathrm{ip}} k_{\mathrm{dcp}}\left(\left\langle U_{\mathrm{dcref}}\right\rangle_{k+1}-\left\langle U_{\mathrm{dc}}\right\rangle_{k+1}\right)-\right.} \\
& k_{\mathrm{ip}} k_{\mathrm{dci}}\left\langle X_{\mathrm{udc}}\right\rangle_{k+1}+2\left(k_{\mathrm{ip}}+j \omega_{\mathrm{s}} L\right)\left\langle I_{a(2)}\right\rangle_{k}- \\
& k_{\mathrm{ii}}\left\langle X_{d \mathrm{i}}\right\rangle_{k+1}+2\left\langle U_{\mathrm{sa}(2)}\right\rangle_{k}+j k_{\mathrm{ip}}\left\langle I_{q \mathrm{ref}}\right\rangle_{k+1}+ \\
&\left.j k_{\mathrm{ii}}\left\langle X_{q \mathrm{i}}\right\rangle_{k+1}\right] / 2 k_{\mathrm{pwm}}
\end{aligned}
$$

where $\left\langle U_{\text {dcref }}\right\rangle_{k},\left\langle X_{u \mathrm{dc}}\right\rangle_{k},\left\langle X_{d \mathrm{i}}\right\rangle_{k},\left\langle X_{q \mathrm{i}}\right\rangle_{k},\left\langle I_{d}\right\rangle_{k},\left\langle I_{q}\right\rangle_{k},\left\langle I_{q \text { ree }}\right\rangle_{k}$, $\left\langle U_{d}\right\rangle_{k},\left\langle U_{q}\right\rangle_{k},\left\langle S_{d}\right\rangle_{k}$, and $\left\langle S_{q}\right\rangle_{k}$ are the $k$ th DPs of $u_{\text {dcref }}, x_{\text {udc }}, x_{d i}$, $x_{q i}, i_{d}, i_{q}, i_{q \mathrm{ref}}, u_{d}, u_{q}, s_{d}$, and $s_{q}$.

(13)-(15) and (22)-(26) are the full-order interharmonic analysis model taking controller into account based on DPSCs. If full-order DPSCs model is applied, its order $N$ can be calculated by

$$
N=6 \times 2 \times(p-1)+6,
$$

where $p$ is the ratio of $f_{\text {upp }}$ to $f . f_{\text {upp }}$ is the upper limit frequency of DPSCs model. The schematic diagram of full-order interharmonic analysis model is shown in Fig. 2. This model is divided into five modules which are separated into two types. One is differential equation and the other is algebraic equation. Every module in Fig. 2 is highlighted with the corresponding color of each part in Fig. 1. The variables inside the blue, orange, and purple dotted-line boxes are separately state variables, input variables, and intermediate variables. It should be noted that $\left\langle X_{\text {udc }}\right\rangle_{0},\left\langle X_{d i}\right\rangle_{0},\left\langle X_{q 1}\right\rangle_{0},\left\langle I_{a(1)}\right\rangle_{0},\left\langle I_{a(2)}\right\rangle_{0}$, and $\left\langle U_{\text {dc }}\right\rangle_{0}$ are real numbers so that they only contribute to the order for six.

\section{ORDER-REDUCTION MethoD}

\section{A. Principle of Interharmonic Interaction}

Assumed that there exists background interharmonic voltage with angular frequency $\omega_{\mathrm{s}}+m \omega_{f}$. ( $m$ is a non-zero integer.) The ratio of $m$ to $l$ is not integer. According to Section II, $m$ th DPs of source voltages in $d q$ coordinate are shown by (28).

$$
\left[\begin{array}{l}
\left\langle U_{d}\right\rangle_{m} \\
\left\langle U_{q}\right\rangle_{m}
\end{array}\right]=\left[\begin{array}{cc}
1 & 1 \\
j & -j
\end{array}\right]\left[\begin{array}{c}
0 \\
\left\langle U_{s a(1)}\right\rangle_{l+m}
\end{array}\right]
$$

It is obvious that there exists $m \omega_{f}$ components of modulation wave in $d q$ coordinate if closed-loop control is applied. There exists $m \omega_{f}$ components of modulation wave in $d q$ coordinate when there is low-frequency disturbance of reference dc voltage with angular frequency $m \omega_{f}$ though the source voltages are ideal. According to Section II, the expressions of modulation wave in sequence domain are shown by (29). 
It is shown that there exists $\omega_{\mathrm{s}} \pm m \omega_{f}$ components of modulation wave in sequence domain when there exists background interharmonic voltage with angular frequency $\omega_{\mathrm{s}}+m \omega_{f}$ or there is low-frequency disturbance of reference dc voltage with angular frequency $m \omega_{f}$. Thus, it is supposed that there exists $\omega_{\mathrm{s}}+m \omega_{f}$ components of modulation wave in sequence domain and the inverter applies open-loop control.

$$
\left[\begin{array}{l}
\left\langle S_{a(1)}\right\rangle_{l-m}^{*} \\
\left\langle S_{a(1)}\right\rangle_{l+m}
\end{array}\right]=\frac{1}{2}\left[\begin{array}{l}
\left\langle S_{d}\right\rangle_{m}-j\left\langle S_{q}\right\rangle_{m} \\
\left\langle S_{d}\right\rangle_{m}+j\left\langle S_{q}\right\rangle_{m}
\end{array}\right]
$$

According to (13) and (15), the $k$ th positive DPSCs of inverter-side current is shown as (30) and the $k$ th DPs of dc voltage is shown as (31). It is obvious that there exists the same frequency and sequence component of inverter-side current when there is fundamental positive sequence component of source voltage as shown by (32). It is shown that $\left\langle I_{a(1)}\right\rangle_{l}$ is coupling with $\left\langle U_{\mathrm{dc}}\right\rangle_{0}$ and $\left\langle U_{\mathrm{dc}}\right\rangle_{m}$, so that we need to list the expression of $\left\langle U_{\mathrm{dc}}\right\rangle_{0}$ and $\left\langle U_{\mathrm{dc}}\right\rangle_{m}$ as (33) and (34). As we can see, $\left\langle U_{\mathrm{dc}}\right\rangle_{0}$ is coupling with $\left\langle I_{a(1)}\right\rangle_{l}$ and $\left\langle I_{a(1)}\right\rangle_{l+m} .\left\langle U_{\mathrm{dc}}\right\rangle_{m}$ is coupling with $\left\langle I_{a(1)}\right\rangle_{l},\left\langle I_{a(1)}\right\rangle_{l \pm m}$, and $\left\langle I_{a(1)}\right\rangle_{l+2 m}$.

$$
\begin{aligned}
& \frac{\mathrm{d}\left\langle I_{a(1)}\right\rangle_{k}}{\mathrm{~d} t}=\frac{\left\langle U_{\mathrm{sa}(1)}\right\rangle_{k}}{L}-\frac{1}{2 L}\left(\left\langle S_{a(1)}\right\rangle_{l}\left\langle U_{\mathrm{dc}}\right\rangle_{k-l}+\right. \\
& \left.\left\langle S_{a(1)}\right\rangle_{l+m}\left\langle U_{\mathrm{dc}}\right\rangle_{k-l-m}\right)-\left(\frac{R}{L}+j k \omega_{f}\right)\left\langle I_{a(1)}\right\rangle_{k} \\
& \frac{\mathrm{d}\left\langle U_{\mathrm{dc}}\right\rangle_{k}}{\mathrm{~d} t}=\frac{\left\langle I_{\mathrm{pv}}\right\rangle_{k}}{C_{\mathrm{dc}}}+\frac{3}{2 C_{\mathrm{dc}}}\left(\left\langle S_{a(1)}\right\rangle_{l}\left\langle I_{a(1)}\right)_{l-k}^{*}+\right. \\
& \left\langle S_{a(1)}\right\rangle_{m+l}\left\langle I_{a(1)}\right\rangle_{l+m-k}^{*}+\left\langle S_{a(1)}\right\rangle_{l}^{*}\left\langle I_{a(1)}\right\rangle_{k+l}+ \\
& \left.\left\langle S_{a(1)}\right\rangle_{l+m}^{*}\left\langle I_{a(1)}\right\rangle_{k+l+m}\right)-j k \omega_{f}\left\langle U_{\mathrm{dc}}\right\rangle_{k} \\
& \frac{\mathrm{d}\left\langle I_{a(1)}\right\rangle_{l}}{\mathrm{~d} t}=\frac{\left\langle U_{\mathrm{sa}(1)}\right\rangle_{l}}{L}-\frac{1}{2 L}\left(\left\langle S_{a(1)}\right\rangle_{l}\left\langle U_{\mathrm{dc}}\right\rangle_{0}+\right. \\
& \left.\left\langle S_{a(1)}\right\rangle_{l+m}\left\langle U_{\mathrm{dc}}\right\rangle_{m}^{*}\right)-\left(\frac{R}{L}+j l \omega_{f}\right)\left\langle I_{a(1)}\right\rangle_{l} \\
& \frac{\mathrm{d}\left\langle U_{\mathrm{dc}}\right\rangle_{0}}{\mathrm{~d} t}=\frac{\left\langle I_{\mathrm{pv}}\right\rangle_{0}}{C_{\mathrm{dc}}}+\frac{3}{2 C_{\mathrm{dc}}}\left(\left\langle S_{a(1)}\right\rangle_{l}\left\langle I_{a(1)}\right\rangle_{l}^{*}+\right. \\
& \left\langle S_{a(1)}\right\rangle_{m+l}\left\langle I_{a(1)}\right\rangle_{l+m}^{*}+\left\langle S_{a(1)}\right\rangle_{l}^{*}\left\langle I_{a(1)}\right\rangle_{l}+ \\
& \left.\left\langle S_{a(1)}\right\rangle_{l+m}^{*}\left\langle I_{a(1)}\right\rangle_{l+m}\right) \\
& \frac{\mathrm{d}\left\langle U_{\mathrm{dc}}\right\rangle_{m}}{\mathrm{~d} t}=\frac{\left\langle I_{\mathrm{pv}}\right\rangle_{m}}{C_{\mathrm{dc}}}+\frac{3}{2 C_{\mathrm{dc}}}\left(\left\langle S_{a(1)}\right\rangle_{l}\left\langle I_{a(1)}\right\rangle_{l-m}^{*}+\right. \\
& \left\langle S_{a(1)}\right\rangle_{m+l}\left\langle I_{a(1)}\right\rangle_{l}^{*}+\left\langle S_{a(1)}\right\rangle_{l}^{*}\left\langle I_{a(1)}\right\rangle_{l+m}+ \\
& \left.\left\langle S_{a(1)}\right\rangle_{l+m}^{*}\left\langle I_{a(1)}\right\rangle_{l+2 m}\right)-j m \omega_{f}\left\langle U_{\mathrm{dc}}\right\rangle_{m}
\end{aligned}
$$

The rest can be done in the same manner and it is shown that

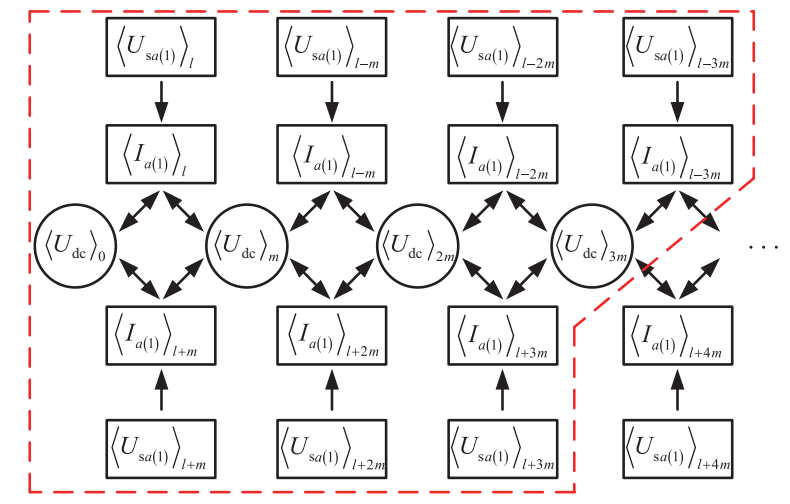

Fig. 3. Principle of interharmonic interaction.

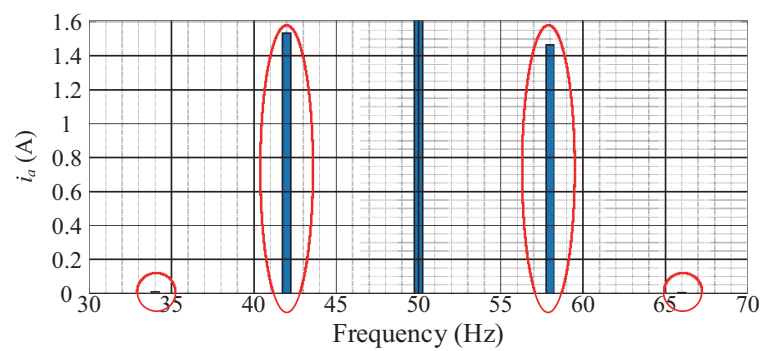

(a) Under disturbance of reference dc voltage

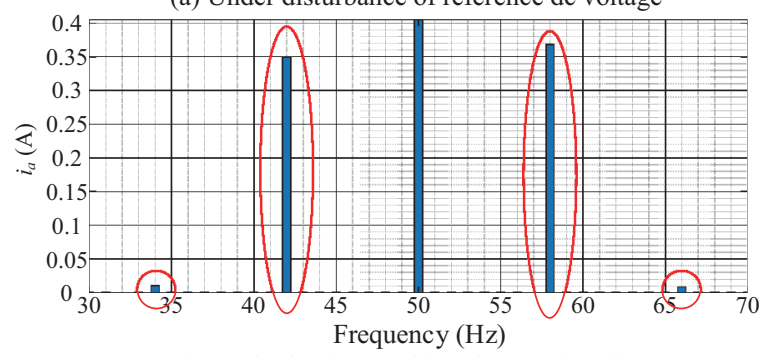

(b) Under background interharmonic voltage

Fig. 4. Spectrograms of inverter-side currents.

there will exist a series components of inverter-side current of $\omega_{\mathrm{s}} \pm m \omega_{f}, \omega_{\mathrm{s}} \pm 2 m \omega_{f}$, and so on. There will exist a series components of dc voltage of $m \omega_{f}, 2 m \omega_{f}$, and so on. Thus, the principle of interharmonic interaction is obtained as presented in Fig. 3. The arrows indicate the relationship of interaction. Two-way arrows indicate that the interaction is mutual.

Generally speaking, the situation is the same as Fig. 3 when there exists one or more components of modulation wave with angular frequency $\omega_{\mathrm{s}}+n m \omega_{f}(n$ is an integer). That the inverter applies closed-loop control when there is background interharmonic voltage or there is low-frequency disturbance of reference dc voltage is the case. There only exists $\omega_{\mathrm{s}} \pm m \omega_{f}$ components of inverter-side current when there is background interharmonic voltage with angular frequency $\omega_{\mathrm{s}}+m \omega_{f}$ in [31] because only the fundamental positive component of modulation wave is taken into account.

\section{B. Reduced-Order Interharmonic Analysis Model}

Given that the interharmonic interaction will fade out with the spectrum component deviating from the fundamental one as the spectrograms shown in Fig. 4. The variables inside the 


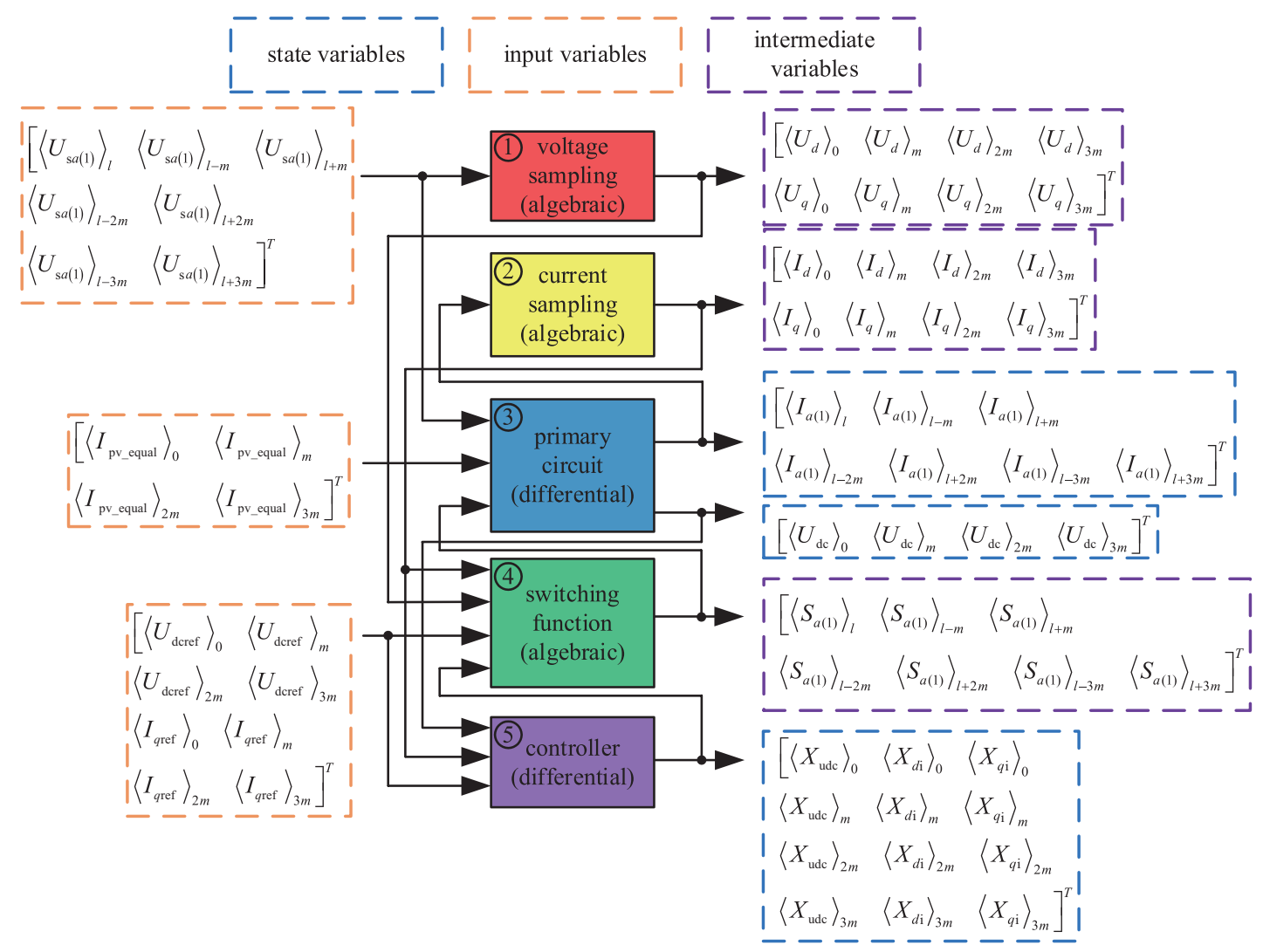

Fig. 5. Schematic diagram of the reduced-order interharmonic analysis model for grid-connected PV system.

red box in Fig. 3 are the dominant frequencies of variables in primary circuit. Thus, we select these variables as the state variables and input variables of DPSCs model. According to (8) and (9), there will exist dc, $m \omega_{f}, 2 m \omega_{f}$, and $3 m \omega_{f}$ components of source voltages and inverter-side currents in $d q$ coordinate. The abovementioned components in $d q$ coordinate will result in $\omega_{\mathrm{s}}, \omega_{\mathrm{s}} \pm m \omega_{f}, \omega_{\mathrm{s}} \pm 2 m \omega_{f}$, and $\omega_{\mathrm{s}} \pm 3 m \omega_{f}$ components of modulation wave.

The state variables, input variables, and corresponding dominant variables in controller are shown together in Fig. 5. The voltage sampling modules and the current sampling modules can be obtained by substituting the $X$ in (8) and (9) with $U$ and $I$ separately. The primary circuit modules are clearly shown in (13)-(15) where we only take $\omega_{\mathrm{s}}, \omega_{\mathrm{s}} \pm m \omega_{f}, \omega_{\mathrm{s}} \pm 2 m \omega_{f}$, and $\omega_{\mathrm{s}} \pm 3 m \omega_{f}$ components of modulation wave into account. The switching function modules are shown in (25) for the previously mentioned components. The controller modules are shown in (22)-(24).

The DPSCs model as shown in Fig. 5 is the reduced-order interharmonic analysis model for grid-connected PV system based on the principle of interharmonic interaction. We can easily count that the order of the model is 42 whatever the frequency of background interharmonic voltage or low-frequency disturbance of reference dc voltage is. Thus, the fundamental frequency of DPSCs model can be selected flexibly even it is small enough because it has no effect on the order of the DPSCs model.
TABLE I

System Parameters

\begin{tabular}{|c|c|c|c|}
\hline Parameter & Value & Parameter & Value \\
\hline$u_{\mathrm{s} a}, u_{\mathrm{s} b}, u_{\mathrm{s} c}$ & $380 \mathrm{~V}(50 \mathrm{~Hz})$ & $k_{\mathrm{dcp}}$ & 0.5 \\
\hline$R$ & $0.1 \Omega$ & $k_{\mathrm{dci}}$ & 15 \\
\hline$L$ & $8 \mathrm{mH}$ & $k_{\text {ip }}$ & 6 \\
\hline$C_{\mathrm{dc}}$ & $3400 \mu \mathrm{F}$ & $k_{\mathrm{ii}}$ & 50 \\
\hline$i_{\mathrm{pv}}$ & $7.444 \mathrm{~A}$ & $k_{\mathrm{pwm}}$ & 375 \\
\hline
\end{tabular}

\section{Simulation Results}

In this section, two examples are described in detail to validate the proposed method in Section III. One is under the lowfrequency disturbance of reference dc voltage. The other is under the background interharmonic voltage. See Table I for the parameters in Fig. 1.

Fig. 6 compares the waveforms of ac current and dc voltage obtained by simulation and reduced-order DPSCs model when there is an $8 \mathrm{~Hz}$ disturbance of reference dc voltage with $10 \mathrm{~V}$ amplitude and the phase is the same as the source voltage. Table II compares the amplitudes and phases of the main interharmonic currents calculated by simulation and reduced-order DPSCs model.

Fig. 6 compares the waveforms of ac current and dc voltage obtained by simulation and reduced-order DPSCs model when there is $42 \mathrm{~Hz}$ background interharmonic voltage with 
TABLE II

Comparison Between Simulation and Reduced-Order DPSCs Model of aC Current Under Reference DC Voltage Disturbance

\begin{tabular}{lccc}
\hline \hline \multicolumn{4}{c}{ Amplitude/Phase } \\
\hline Frequency & \multicolumn{4}{c}{ Simulation } & \multicolumn{1}{c}{ Calculation } & Error \\
\hline $34 \mathrm{~Hz}$ & $0.0092 \mathrm{~A} /-85.6^{\circ}$ & $0.0091 \mathrm{~A} /-86.4^{\circ}$ & $-1.10 \% /-0.80^{\circ}$ \\
$42 \mathrm{~Hz}$ & $0.3495 \mathrm{~A} / 29.6^{\circ}$ & $0.3500 \mathrm{~A} / 29.7^{\circ}$ & $0.14 \% / 0.10^{\circ}$ \\
$58 \mathrm{~Hz}$ & $0.3681 \mathrm{~A} /-25.7^{\circ}$ & $0.3689 \mathrm{~A} /-25.7^{\circ}$ & $0.22 \% / 0.00^{\circ}$ \\
$66 \mathrm{~Hz}$ & $0.0087 \mathrm{~A} / 98.6^{\circ}$ & $0.0089 \mathrm{~A} / 101^{\circ}$ & $2.30 \% / 2.40^{\circ}$ \\
\hline
\end{tabular}

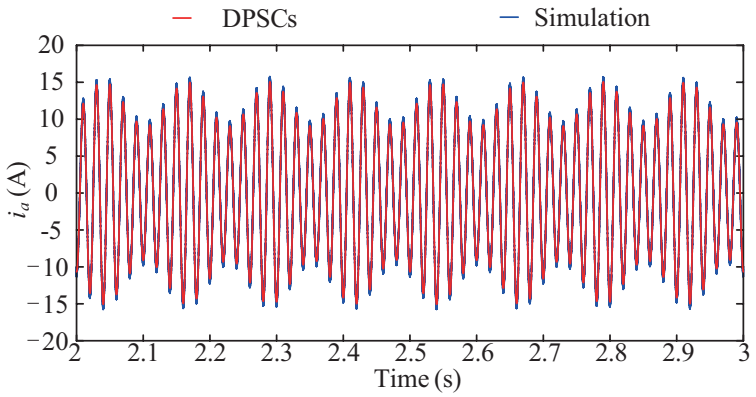

(a) Waveform of ac current

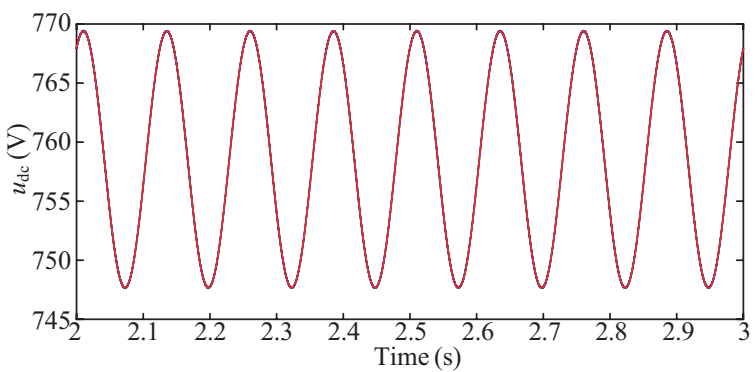

(b) Waveform of dc voltage

Fig. 6. Time domain waveforms under reference dc voltage disturbance.

TABLE III

Comparison Between Simulation and Reduced-order DPSCs Model of AC Current Under BaCKGround InTERharmonic Voltage

\begin{tabular}{lccc}
\hline \hline \multicolumn{4}{c}{ Amplitude/Phase } \\
\hline Frequency & Simulation & Calculation & Error \\
\hline $34 \mathrm{~Hz}$ & $0.0121 \mathrm{~A} / 31.7^{\circ}$ & $0.0123 \mathrm{~A} / 32.7^{\circ}$ & $1.65 \% / 1.00^{\circ}$ \\
$42 \mathrm{~Hz}$ & $1.5351 \mathrm{~A} /-62.6^{\circ}$ & $1.5352 \mathrm{~A} /-62.6^{\circ}$ & $0.00 \% / 0.00^{\circ}$ \\
$58 \mathrm{~Hz}$ & $1.4641 \mathrm{~A} / 62.9^{\circ}$ & $1.4639 \mathrm{~A} / 62.9^{\circ}$ & $-0.01 \% / 0.00^{\circ}$ \\
$66 \mathrm{~Hz}$ & $0.0070 \mathrm{~A} / 15.5^{\circ}$ & $0.0065 \mathrm{~A} / 12.1^{\circ}$ & $-7.14 \% /-3.40^{\circ}$ \\
\hline \hline
\end{tabular}

$5 \%$ amplitude of the fundamental one and the phase is the same as the source voltage. Table III compares the amplitudes and phases of the main interharmonic currents calculated by simulation and reduced-order DPSCs model.

Figs. 6 and 7, Tables II and III show an excellent agreement between simulation and reduced-order DPSCs model when there is background interharmonic voltage or there is lowfrequency disturbance of reference dc voltage.

According to (27), the upper limit frequency is set to be $150 \mathrm{~Hz}$ and the fundamental frequency is set to be $1 \mathrm{~Hz}$. Table IV compares the order and the calculation time via simulation,

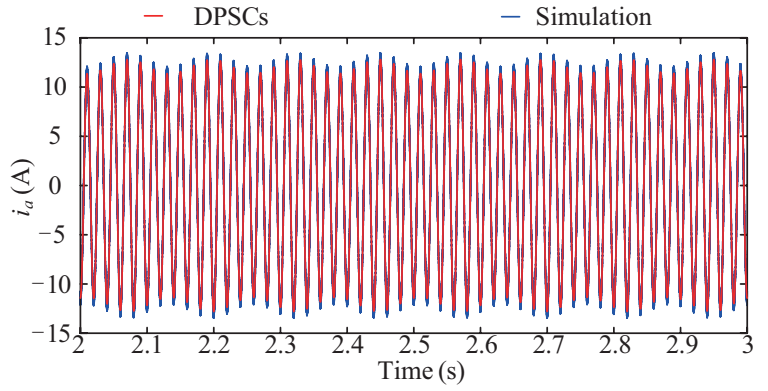

(a) Waveform of ac current

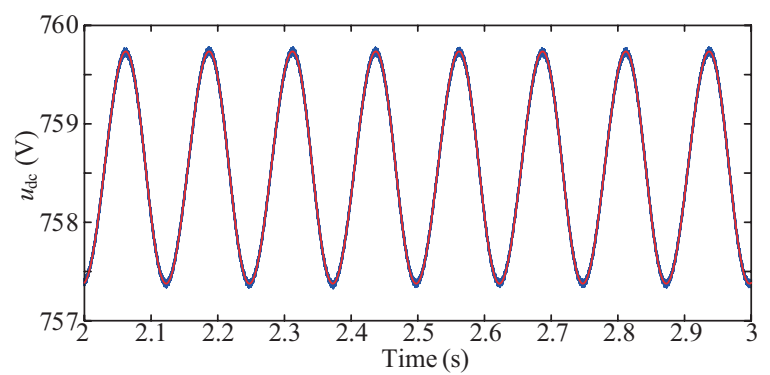

(b) Waveform of dc voltage

Fig. 7. Time domain waveforms under background interharmonic voltage.

TABLE IV

Comparison Between Simulation, Full-Order DPSCs, and Reduced-Order DPSCs Model of Order and Calculation Time

\begin{tabular}{lcccc}
\hline & Time interval/s & $\Delta t / \mu \mathrm{s}$ & Order & Calculation time/s \\
\hline Simulation & 3 & 0.1 & - & 55.4 \\
$\begin{array}{l}\text { Full-order DPSCs } \\
\text { Reduced-order }\end{array}$ & 2 & 100 & 1794 & 307.9 \\
\begin{tabular}{l} 
DPSCs \\
\hline
\end{tabular} & 2 & 100 & 42 & 9.9 \\
\hline
\end{tabular}

full-order DPSCs, and reduced-order DPSCs model using a computer with i5-7400 CPU, 3.0 GHz, and 8 GB RAM. It is shown that the dimensions of the full-order DPSCs model explode when considering the interharmonics. Simulation results require a post-processing routine to obtain the interharmonic content, i.e., using a windowed fast Fourier transform (WFFT) algorithm so that the time interval of it is $3 \mathrm{~s}$ [32].

The reduced-order DPSCs model can guarantee the accuracy and speeds up the calculation at the same time so that the orderreduction method of interharmonic analysis based on the principle of interharmonic interaction is validated.

\section{CONCLUSION}

In this paper, an order-reduction method of interharmonic analysis model based on the principle of interharmonic interaction has been proposed. The interharmonic emission characteristics of grid-connected PV system when considering the impact of controller is different from that only the fundamental positive component of modulation wave is taken into account. The reduced-order interharmonic analysis model calculates the interharmonic currents accurately when there is background interharmonic voltage or there is low-frequency disturbance of reference dc voltage. The reduced-order interharmonic analysis 
model based on the principle of interharmonic interaction shows substantial computational savings while keeping accuracy.

$$
\begin{aligned}
& \text { ApPendix } \\
& \frac{\mathrm{d}\left\langle X_{\text {udc }}\right\rangle_{k}}{\mathrm{~d} t}=\left\langle U_{\text {dcref }}\right\rangle_{k}-\left\langle U_{\text {dc }}\right\rangle_{k}-j k \omega_{f}\left\langle X_{\text {udc }}\right\rangle_{k} \\
& \frac{\mathrm{d}\left\langle X_{d \mathrm{i}}\right\rangle_{k}}{\mathrm{~d} t}=k_{\mathrm{dcp}}\left(\left\langle U_{\text {deref }}\right\rangle_{k}-\left\langle U_{\mathrm{dc}}\right\rangle_{k}\right)+k_{\mathrm{dci}}\left\langle X_{\text {udc }}\right\rangle_{k}- \\
& \left\langle I_{d}\right\rangle_{k}-j k \omega_{f}\left\langle X_{d \mathrm{i}}\right\rangle_{k} \\
& \frac{\mathrm{d}\left\langle X_{q \mathrm{i}}\right\rangle_{k}}{\mathrm{~d} t}=\left\langle I_{q \mathrm{ref}}\right\rangle_{k}-\left\langle I_{q}\right\rangle_{k}-j k \omega_{f}\left\langle X_{q \mathrm{i}}\right\rangle_{k} \\
& \left\langle S_{d}\right\rangle_{k}=\left\{-k_{\text {ip }}\left[k_{\text {dcp }}\left(\left\langle U_{\text {dcref }}\right\rangle_{k}-\left\langle U_{\text {dc }}\right\rangle_{k}\right)+\right.\right. \\
& \left.k_{\mathrm{dci}}\left\langle X_{\mathrm{udc}}\right\rangle_{k}-\left\langle I_{d}\right\rangle_{k}\right]-k_{\mathrm{ii}}\left\langle X_{d \mathrm{i}}\right\rangle_{k}+ \\
& \left.\omega_{\mathrm{s}} L\left\langle I_{q}\right\rangle_{k}+\left\langle U_{d}\right\rangle_{k}\right\} / k_{\mathrm{pwm}} \\
& \left\langle S_{q}\right\rangle_{k}=\left[-k_{\text {ip }}\left(\left\langle I_{q \text { ref }}\right\rangle_{k}-\left\langle I_{q}\right\rangle_{k}\right)-k_{\text {ii }}\left\langle X_{q \mathrm{i}}\right\rangle_{k}-\right. \\
& \left.\omega_{\mathrm{s}} L\left\langle I_{d}\right\rangle_{k}+\left\langle U_{q}\right\rangle_{k}\right] / k_{\mathrm{pwm}}
\end{aligned}
$$

Please refer to Section II for parameter definition.

\section{REFERENCES}

[1] A. Chidurala, T. K. Saha, and N. Mithulananthan. "Harmonic impact of high penetration photovoltatic system on unbalanced distribution networks-learning from an urban photovoltaic network," in IET Renewable Power Generation, vol. 10, no. 4, pp. 485-494, Apr. 2016.

[2] R. Langella, A. Testa, J. Meyer, F. Moller, R. Stiegler, and S. Z. Djokic, "Experimental-based evaluation of PV inverter harmonic and interharmonic distortion due to different operating conditions," in IEEE Transactions on Instrumentation Measurement, vol. 65, no. 10, pp. 2221-2233, Oct. 2016.

[3] C. Larose, R. Gagnon, P. P. Homme, M. Fecteau, and M. Asmine, "Type-III wind power plant harmonic emissions: field measurements and aggregation guidelines for adequate representation of harmonics," in IEEE Transactions on Sustainable Energy, vol. 4, no. 3, pp. 797-804, Jul. 2013.

[4] S. Djurovic, D. S. Vilchis-Rodriguez, and A. C. Smith, "Supply induced interharmonic effects in wound rotor and doubly-fed induction generators," in IEEE Transactions on Energy Conversion, vol. 30, no. 4, pp. 1397-1408, Dec. 2015.

[5] V. Ravindran, T. Bussatto, S. K. Ronnberg, J. Meyer, and M. H. J. Bollen, "Time-varying interharmonics in different types of grid-tied PV inverter systems," in IEEE Transactions on Power Delivery, vol. 35, no. 2, pp. 483-396, Apr. 2020.

[6] C. $\mathrm{Li}$, "Unstable operation of photovoltaic inverter from field experiences," in IEEE Transactions on Power Delivery, vol. 33, no. 2, pp. 1013-1015, Apr. 2018.

[7] J. Drapela, R. Langella, J. Slezingr, and A. Testa, "Tunable flickermeter to account for different lamp technologies," in IEEE Transactions on Power Delivery, vol. 32, no. 2, pp. 872-880, Apr. 2017.

[8] F. Zavoda, S. Rnnberg, M. Bollen, J. Meyer, and J. Desmet, "Power quality and EMC issues with future electricity networks," CIGRE., Paris, FR, Tech Bro. 978-2-85873-421-4, Mar. 2018.

[9] V. Ravindran, S. K. Ronnberg, and M. H. J. Bollen, "Interharmonics in PV systems: a review of analysis and estimation methods; considerations for selection of an APT method," in IET Renewable Power Generation, vol. 13, no. 12, pp. 2023-2032, Sept. 2019.

[10] J. Smith, S. Rönnberg, M. Bollen, J. Meyer, and A. Blanco, "Power quality aspects of solar power-results from CIGRE JWG C4/C6.29," CIGRE., Paris, FR, Tech Bro. 978-2-85873-375-0, Dec. 2016.

[11] A. Sangwongwanich, Y. Yang, D. Sera, and F. Blaabjerg, "Interharmonics from grid-connected PV systems: Mechanism and mitigation," in Proceedings of 2017 IEEE 3rd International Future Energy Electronics Conference and ECCE Asia (IFEEC 2017 - ECCE Asia), Kaohsiung, TWN, 2017, pp. 722-727.

[12] A. Sangwongwanich and F. Blaabjerg, "Interharmonics reduction in photovoltaic systems with random sampling MPPT technique," in Proceedings of 2019 IEEE Energy Conversion Congress and Exposition (ECCE), Baltimore, MD, 2019, pp. 4760-4765.

[13] A. Sangwongwanich and F. Blaabjerg, "Mitigation of interharmonics in PV systems with maximum power point tracking modification," in IEEE Transactions on Power Electronics, vol. 34, no. 9, pp. 8279-8282, Sept. 2019.

[14] Y. Pan, A. Sangwongwanich, Y. Yang, and F. Blaabjerg, "A phaseshifting MPPT to mitigate interharmonics from cascaded H-bridge PV inverters," in IEEE Transactions on Industrial Applications, vol. 57, no. 3, pp. 3052-3063, May-Jun. 2021.

[15] Y. Pan, A. Sangwongwanich, Y. Yang, and F. Blaabjerg, "A series interharmonic filter for cascaded H-bridge PV inverters," in Proceedings of 2020 IEEE Energy Conversion Congress and Exposition (ECCE), Detroit, MI, 2020, pp. 341-346.

[16] A. Sangwongwanich, Y. Yang, D. Sera, H. Soltani, and F. Blaabjerg, "Analysis and modeling of interharmonics from grid-connected photovoltatic systems," in IEEE Transactions on Power Electronics, vol. 33, no. 10, pp. 8353-8364, Oct. 2018.

[17] M. Li and X. Wang, "The spectral analysis of stator interharmonic currents of induction motors with oscillating mechanical loads," in International Transactions on Electrical Energy Systems, vol. 24, no. 8, pp. 1194-1216, Jul. 2014.

[18] G. W. Chang, S. Chen, H. Su, and P. Wang, "Accurate assessment of harmonic and interharmonic currents generated by VSI-Fed drives under unbalanced supply voltages," in IEEE Transactions on Power Delivery, vol. 26, no. 2, pp. 1083-1091, Apr. 2011.

[19] S. Tao, L. Yao, K. Liao, and X. Xiao, "Analytical model for interharmonic current caused by DC voltage disturbance of photovoltaic inverter," in Power System Technology, vol. 42, no. 3, pp. 878-885, Mar. 2018.

[20] Q. Zhong, Q. Shi, G. Wang, and H. Li, "Interharmonic analysis model of photovoltaic grid-connected system based on perturbed MPPT control," in Proceedings of the Chinese Society of Electrical Engineering, vol. 38, no. 22, pp. 6533-6541, Nov. 2018.

[21] J. J. Rico, M. Madrigal, and E. Acha, "Dynamic harmonic evolution using the extended harmonic domain," in IEEE Transactions on Power Delivery, vol. 18, no. 2, pp. 587-594, Apr. 2003.

[22] S. R. Sanders, J. M. Noworolski, X. Z. Liu, and G. C. Verghese, "Generalized averaging method for power conversion circuits," in IEEE Transactions on Power Electronics, vol. 6, no. 2, pp. 251-259, Apr. 1991.

[23] V. A. Caliskan, O. C. Verghese, and A. M. Stankovic, "Multifrequency averaging of DC/DC converters," in IEEE Transactions on Power Electronics, vol. 14, no. 1, pp. 124-133, Jan. 1999.

[24] P. Mattavelli and A. M. Stankovic, "Dynamical phasors in modeling and control of active filters," in Proceedings of 1999 IEEE International Symposium on Circuits and Systems (ISCAS), Orlando, FL, 1999, pp. 278-282.

[25] Q. Zhong, L. Lin, G. Wang, Y. Zhang, and Z. Wu, "Harmonic analysis model for voltage source converter under unbalanced conditions," in IET Generation Transmission \& Distribution, vol. 9, no. 1, pp. 12-21, Jan. 2015.

[26] A. Ramirez, "The modified harmonic domain: interharmonics," in IEEE Transactions on Power Delivery, vol. 26, no. 1, pp. 235-241, Jan. 2011.

[27] U. Vargas, A. Ramirez, and G. C. Lazaroiu, "Flexible harmonic domain model of a photovoltaic system for steady-state analysis," in Proceedings of 2017 International Conference on Energy and Environment, Bucharest, 2017, pp. 311-315.

[28] U. Vargas, A. Ramirez, and G. C. Lazaroiu, "Flexible extended harmonic domain approach for transient state analysis of switched systems," in Electric Power System Research, vol. 155, no. 1, pp. 40-47, Feb. 2018

[29] U. Vargas, A. Ramirez, and G. C. Lazaroiu, "Interharmonic and harmonic steady-state computation of a grid-tied photovoltaic system," in Proceedings of 2019 International Conference on Energy and Environment, Timisoara, Timis, 2019, pp. 234-238. 
[30] U. Vargas, A. Ramirez, G. C. Lazaroiu, and M. Roscia, "Interharmonic modeling and simulation via the flexible extended harmonic domain," in Proceedings of 2019 IEEE Milan PowerTech, Milan, Italy, 2019, pp. 1-6.

[31] Q. Zhong, Y. Qiu, Y. Zhao, H. Li, G. Wang, and F. Wen, "Interharmonic analysis model for photovoltaic grid-connected system with extended dynamic phasors," in Journal of Modern Power System and Clean Energy, early access.

[32] G. T. Heydt, P. S. Fjeld, C. C. Liu, D. Pierce, L. Tu, and G. Hensley, "Applications of the windowed FFT to electric power quality assessment," in IEEE Transactions on Power Delivery, vol. 14, no. 4, pp. 1411-1416, Oct. 1999.

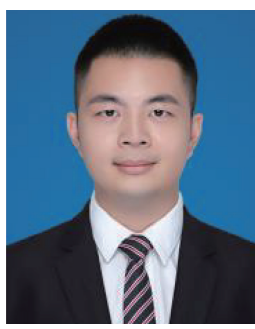

Qingtian Luo was born in Wuzhou, Guangxi, China, in 1996. He received the B.S. degree in electrical engineering from Hunan University, Changsha, China, in 2018. He is currently pursuing the M.S. degree in electrical engineering and automation in South China University of Technology, Guangzhou, China. His research interests include power quality, power electronics control, and interharmonic analysis of grid-connected PV system.

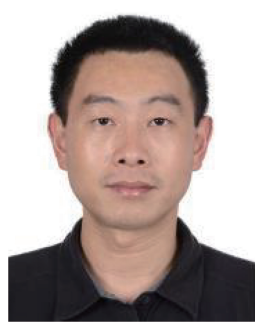

Qing Zhong received M.S. and Ph.D. degrees in South China University of Technology, Guangzhou, China in 2003 and 2000, and B.S. degree in North China University of Technology, Beijing, China, in 1997, all in electrical engineering. He is now a Professor in School of Electric Power, South China University of Technology. His main research interests include power quality and power electronics control.

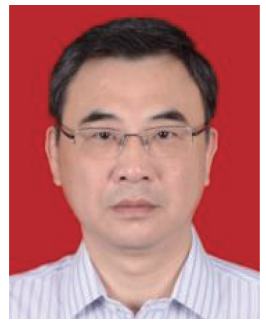

Gang Wang received the Ph.D. degree in electrical engineering and automation from Tianjin University, Tianjin, China, in 1998.

$\mathrm{He}$ is currently a Professor with the School of Electric Power Engineering, South China University of Technology, Guangzhou, China. He is the Director of the Power Engineering and Technology Research and Development Center, Guangdong, China. His major research interests include power system protection and control, fault analysis, power system planning and reliability, and high-voltage direct current technology.

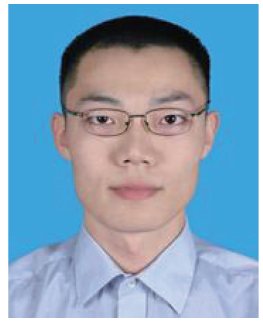

Longjun Wang received the Ph.D. degree in electrical engineering from the South China University of Technology, Guangzhou, China, in 2010. He is currently a Lecturer with the School of Electric Power Engineering, South China University of Technology His major research interests include power system reliability and planning, and artificial intelligence application. 